\title{
The Role of RUNX2 in Osteosarcoma Oncogenesis
}

\author{
J. W. Martin, ${ }^{1}$ M. Zielenska, ${ }^{2}$ G. S. Stein, ${ }^{3}$ A. J. van Wijnen, ${ }^{3}$ and J. A. Squire ${ }^{1}$ \\ ${ }^{1}$ Department of Pathology and Molecular Medicine, Queen's University, Kingston, ON, Canada K7L 3N6 \\ ${ }^{2}$ Department of Pathology and Laboratory Medicine, Hospital for Sick Children, Toronto, ON, Canada M5G 1X8 \\ ${ }^{3}$ Department of Cell Biology, University of Massachusetts Medical School, Worcester, MA 01655, USA
}

Correspondence should be addressed to J. A. Squire, squirej@queensu.ca

Received 15 September 2010; Accepted 29 October 2010

Academic Editor: Stephen Lessnick

Copyright @ $\odot 2011$ J. W. Martin et al. This is an open access article distributed under the Creative Commons Attribution License, which permits unrestricted use, distribution, and reproduction in any medium, provided the original work is properly cited.

\begin{abstract}
Osteosarcoma is an aggressive but ill-understood cancer of bone that predominantly affects adolescents. Its rarity and biological heterogeneity have limited studies of its molecular basis. In recent years, an important role has emerged for the RUNX2 "platform protein" in osteosarcoma oncogenesis. RUNX proteins are DNA-binding transcription factors that regulate the expression of multiple genes involved in cellular differentiation and cell-cycle progression. RUNX2 is genetically essential for developing bone and osteoblast maturation. Studies of osteosarcoma tumours have revealed that the RUNX2 DNA copy number together with RNA and protein levels are highly elevated in osteosarcoma tumors. The protein is also important for metastatic bone disease of prostate and breast cancers, while RUNX2 may have both tumor suppressive and oncogenic roles in bone morphogenesis. This paper provides a synopsis of the current understanding of the functions of RUNX2 and its potential role in osteosarcoma and suggests directions for future study.
\end{abstract}

\section{Introduction}

Osteosarcoma is an aggressive cancer of bone with unknown etiology and often poor clinical outcome. It is the most common primary malignant tumour of bone, representing about $35 \%$ of bone cancer cases [1], and it predominantly affects individuals in their second decade of life. Most often, tumours arise from osteoid-producing neoplastic cells in the metaphyses of the long bones, including the distal femur and proximal humerus [1], and less commonly in the axial skeleton and other nonlong bones [2]. Tumours frequently possess cells with extensive, complex genomic rearrangements, and few consistent changes have been observed across this heterogeneous disease.

No molecules for targeted therapy have been developed for osteosarcoma, and survival rates have not improved for several decades since the introduction of chemotherapy to treatment of the disease (reviewed in [3]). The current standard of care comprises limb-sparing surgery and combination neoadjuvant chemotherapy consisting of high dose methotrexate, doxorubicin, cisplatin, and ifosfamide [4]. Treatment of the bone tumours prior to the use of chemotherapy was solely surgical with a higher percentage of cases undergoing amputation and with an associated 5-year survival of about $15 \%[3,5]$.

Ongoing studies continue to detect genes whose protein products may play a role in osteosarcoma oncogenesis and may have potential as therapeutic targets. The tumour suppressors p53 and pRB are inactivated at the DNA level in roughly $50 \%-70 \%$ of sporadic osteosarcomas [6], and germline inactivations of either of those proteins significantly increase risk for developing osteosarcoma [6, 7]. For example, Li-Fraumeni patients, who have p53 germ line mutations, have an increased incidence of osteosarcoma $[8,9]$. A similar situation arises with RecQL helicase inactivations [6], which are also associated with chromosomal instability in osteosarcoma tumours [10]. This tumour is also characterised by a vastly heterogeneous array of complex genomic rearrangements, but their description is beyond the scope of this paper and can be retrieved in reports by our lab and others [11-21].

For the purpose of this paper, it will suffice to call attention to the chromosomal region 6p12-p21, which encompasses the RUNX2 gene and experiences recurrent gain and amplification in osteosarcoma [11-17, 22]. In our lab, we have detected amplification-related overexpression 
of the RUNX2 gene in a subset of osteosarcoma tumours and identified a correlation between high RUNX2 mRNA overexpression and poor tumour response to chemotherapy based on the percentage of tumour necrosis following treatment [23]. This prospective estimate of response is an indirect predictor of response that is routinely used as part of patient management. In a separate retrospective cohort of osteosarcoma patient specimens, we have also detected correlations between copy number gain of RUNX2 and poor tumour necrosis in response to chemotherapy (measured by fluorescence in situ hybridisation) and between high RUNX2 protein levels and poor chemoresponse in the tumours [paper in preparation]. Furthermore, RUNX2 protein levels appear to be selectively deregulated in several osteosarcomaderived cell culture models [24-27]. RUNX2/RUNX2 thus has potential as a predictive biomarker for osteosarcoma, but a better understanding of the gene and protein in the context of the disease is necessary before considering targeted treatments and diagnostic, prognostic, and predictive tests.

\section{RUNX Family of Transcription Factor Genes}

The three members of the mammalian RUNX family of tissue-specific transcription factor genes encode the DNAbinding $\alpha$ components of the core-binding factor (CBF) complex [28]. In the literature, the genes are also known by the family names core-binding factor- $\alpha$ (CBFA), acute myeloid leukemia $(A M L)$, and mouse polyoma enhancerbinding protein $2 \alpha$ (PEBP $2 \alpha)$, depending on the context of their study [29]. The RUNX proteins, as part of the CBF complex, regulate differentiation, survival, and growth in a variety of tissues, but are specifically essential for definitive hematopoiesis (RUNX1), osteogenesis (RUNX2), as well as neurogenesis and gut development (RUNX3) (reviewed in [30]). RUNX1/AML1/CBFA2/PEBP2 $\alpha B$ was discovered as a common chromosomal translocation target in chronic myelogenous and acute myeloid leukemias (reviewed in [31]), and its critical necessity for adult blood-cell production was discovered in RUNX1-null mice, which lacked definitive hematopoiesis [32, 33]. RUNX3/AML2/CBFA3/PEBP $2 \alpha C$ expression is necessary for development of neuronal networks [34, 35] and the gastrointestinal tract [36], and its inactivation is strongly associated with gastric cancer [37]. RUNX2/AML3/CBFA1/PEBP2 $\alpha A$ encodes an essential determinant of osteoblast differentiation $[38,39]$ that regulates the expression of many genes during bone development (reviewed in [40]).

\section{RUNX2 Structure-Function Relationship}

The RUNX2 gene occupies approximately $220 \mathrm{kbp}$ on chromosome 6 near the border between cytobands 6p21.1 [28, 41] and 6p12.3 (UCSC Genome Browser, March 2006 hg18 assembly), and the RUNX2 protein exists as two major isoforms [42] (Figure 1). Two distinct promoters for the RUNX2 gene, $\mathrm{P} 1$ and $\mathrm{P} 2$, give rise to two biologically unique transcripts [43] (Figure 1(b)), and alternative splicing contributes to at least three variants of the protein based on the at least eight exons known to make up the gene $[41,44]$ (Figure 1(b)). The RUNX2 gene is a unique member of the RUNX family in that it produces the largest protein product (521 amino acids) [45], which possesses two domains distinct from its homologues: a short stretch of glutaminealanine (QA) repeats at the $\mathrm{N}$-terminus and a C-terminal proline/serine/threonine (PST) rich tract, both regions of which are necessary for full transactivation activity [46]. However, the protein has high-sequence identity with the other RUNX proteins, sharing with them the DNA-binding Runt domain, the nuclear localisation signal (NLS), the nuclear matrix targeting signal (NMTS), and a C-terminal VWRPY sequence, which allows interaction with corepressors transducin-like enhancer of split (TLE)/Groucho [47, 48] (Figure 1(c)).

The Runt domain is common among the RUNX proteins [51], and was first characterised in the Runt and Lozenge proteins of Drosophila, in which they are essential for the regulation of many developmental processes, including segmentation, sex determination, and hematopoiesis (reviewed in [52]). This domain confers the ability for binding to DNA and for heterodimerisation with $\mathrm{CBF} \beta[53]$ to form the CBF complex. The $\mathrm{CBF} \beta$ protein, though necessary for RUNX activity, does not directly affect transcription regulation itself, but rather allosterically increases the DNA-binding capacity of its RUNX partner [54, 55].

RUNX2 binds specific cis-acting elements via the conserved Runt domain to enhance transcription of genes in many tissues during embryogenesis, particularly in Tlymphocytes throughout development of the thymus [56] and developing cartilage [57]. However, its most significant function is in the regulation of osteoblast differentiation during bone development [45].

\section{Importance of RUNX2 in Normal Skeletal Development}

The significance of RUNX2 in skeletal development was first suggested by studies of the autosomal dominant disease cleidocranial dysplasia (CCD). Initially, linkage studies of kindreds with CCD led to the discovery that a single locus within cytoband 6p21 was associated with the disease [58, 59]. Higher resolution cytogenetic and sequencing analyses subsequently identified several mechanisms for heterozygous inactivation of the RUNX2 gene: in-frame polyalanine expansions within the QA domain, heterozygous deletions due to chromosomal inversion, nonsense mutations, missense mutations, and frameshift mutations due to insertion or microdeletion, all of which resulted in RUNX2 haploinsufficiency [60, 61]. Mouse studies demonstrated conclusively that RUNX2 was necessary for normal bone development. Mice heterozygous for mutant RUNX2 recapitulate human $\mathrm{CCD}$, and mice homozygous for mutant RUNX2 were deficient in osteoblasts and vascularisation of marrow due to a lack of osteoblast and endothelial differentiation of periosteal mesenchymal stem cells (MSCs) $[38,39,62,63]$. 


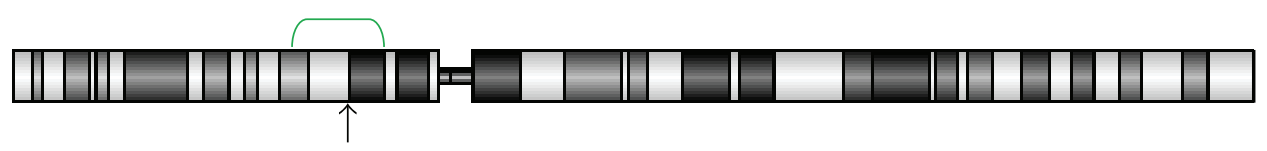

(a)

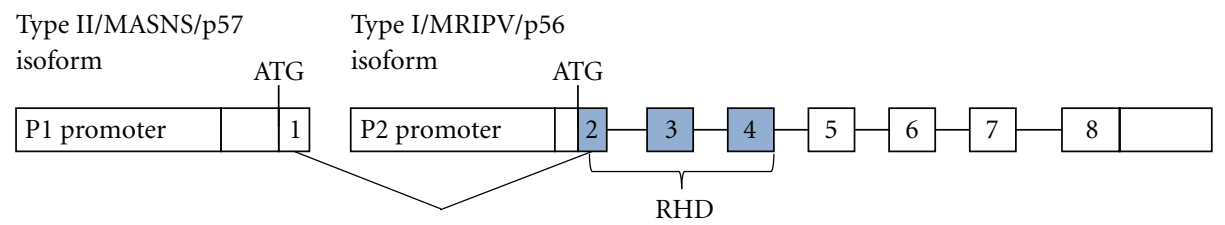

(b)

Type II/MASNS/p57 isoform

\begin{tabular}{|l|l|l|l|l|l|l|l|l|l|l|}
\hline MASNS & QA-rich tract & & RHD & NLS & & PST-rich tract & NMTS & & VWRPY \\
\hline
\end{tabular}

(c)

Figure 1: Chromosome 6 and RUNX2/RUNX2. (a) Chromosome 6 and location of RUNX2. The green bracket approximately spans the minimal common region of gain identified by array comparative genomic hybridisation (aCGH) studies of osteosarcomas, between cytobands 6p21.2 to 6p12.3 (spanning nucleotide positions 36,800,000 bp to 51,100,000 bp, resp.). All genomic information was obtained from UCSC Genome Browser (http://genome.ucsc.edu/), March 2006 (hg18) assembly. (b) Gene structure of RUNX2. Major isoforms MASNS and MRIPV are transcribed starting from promoters P1 and P2, respectively, and ATG indicates the start codon. The MRIPV isoform is encoded from exons $2-8$, while the MASNS isoform is encoded from all eight exons. The Runt homology domain (RHD) is encoded from portions of exons 2, 3 and 4 (shaded). (c) Protein structure of RUNX2. The Type II/p57 isoform comprises 521 amino acids and begins with the bone-specific N-terminal MASNS polypeptide. It has a glutamine/alanine (QA) rich tract and a proline/serine/threonine (PST) rich tract that are both unique to RUNX2 in the RUNX family of proteins. The protein also possesses the RHD DNA-binding domain, the nuclear-localisation signal (NLS), the nuclear matrix targeting signal (NMTS), and the C-terminal VWRPY domain for TLE/Groucho corepressor interactions. Adapted from $[44,45,49,50]$.

In its capacity as a transcription factor necessary for osteoblast differentiation $[64,65]$ and full skeletal development $[38,39]$, RUNX2 acts as a "platform protein," in that it interacts with a variety of coactivator and corepressor proteins, including chromatin remodeling factors and epigenetic modifiers (reviewed in [45]). Transcriptional regulation of RUNX2 is also complex and affected by a variety of signaling pathways (a summary of protein-protein interactions and transcriptional regulators of RUNX2 is shown in Figure 2). The complexity of RUNX2 signaling is further compounded by its autorepression [49], by its presence in at least two isoforms, and by its emerging relevance in the development of nonosteogenic cells [66].

\section{Upstream Signaling and Transcription Regulation of RUNX2}

Discrete RUNX2 transcriptional activity is necessary for all stages of osteogenesis, and expression of the MASNS/p57 (Type II) isoform from the osteoblast-specific P1 promoter leads to the osteoblast-specific isoform of the protein [67]. The MRIPV/p56 (Type I) isoform of RUNX2, expressed from the chondrocyte-specific P2 promoter [68], is required for chondrocyte hypertrophy and maturation, in a role subject to repression by the chondrocyte-specific transcription factor SOX9 [69, 70]. Upstream RUNX2 promoter elements bind a variety of factors which form important branches of embryogenic pathways, including Hedgehog (Hh), canonical Wnt, mitogen-activated protein kinase (MAPK), fibroblast growth factor (FGF), and bone morphogenetic protein (BMP)/transforming growth factor $\beta$ (TGF $\beta$ ) (Figure 2 ).

During endochondral ossification, one of the first events to begin differentiation of osteoprogenitor cells from MSCs is the transcriptional activation of RUNX2 by Indian hedgehog (Ihh) [71, 72], which is itself upregulated by RUNX2 [73]. Other essential signals are the insulin-like growth factors (IGFs), which are implicated in early osteogenesis. IGF signaling activates the phosphatidylinositol 3-kinase (PI3K)Akt pathway, with AKT2 being required for both BMP2 signaling and for RUNX2 transcriptional activation [74, 75]. The canonical Wnt protein T-cell factor 1 (TCF1), with betacatenin, also upregulates RUNX2 expression in MSCs [76], but further studies have shown that Wnt signaling is most critical in the transition from RUNX2+Osterix1osteoprogenitors to RUNX2+Osterix1+ cells [77], and in subsequent osteoblast maturation [72].

During progression of osteogenesis, numerous other factors regulate the expression of RUNX2. SP1, ETS1, and ELK1 all stimulate RUNX2 expression, the former two predominating during osteoblast proliferation and early differentiation, and the latter protein maintaining basal RUNX2 transcriptional activity in later stages of differentiation [78]. Transcriptional activation of RUNX2 is also facilitated by the BMP2 signaling cascade via the homeodomain proteins DLX3 and DLX5 [79] and by MAPK/Ras/ERK signaling in response to mechanical stress $[80,81]$. FGFs stimulate bone formation through the protein kinase $\mathrm{C}$ (PKC) pathway, with FGF2/FGFR2 activating expression of $R U N X 2$, as well as transcriptional activity of the RUNX2 protein [82]. 


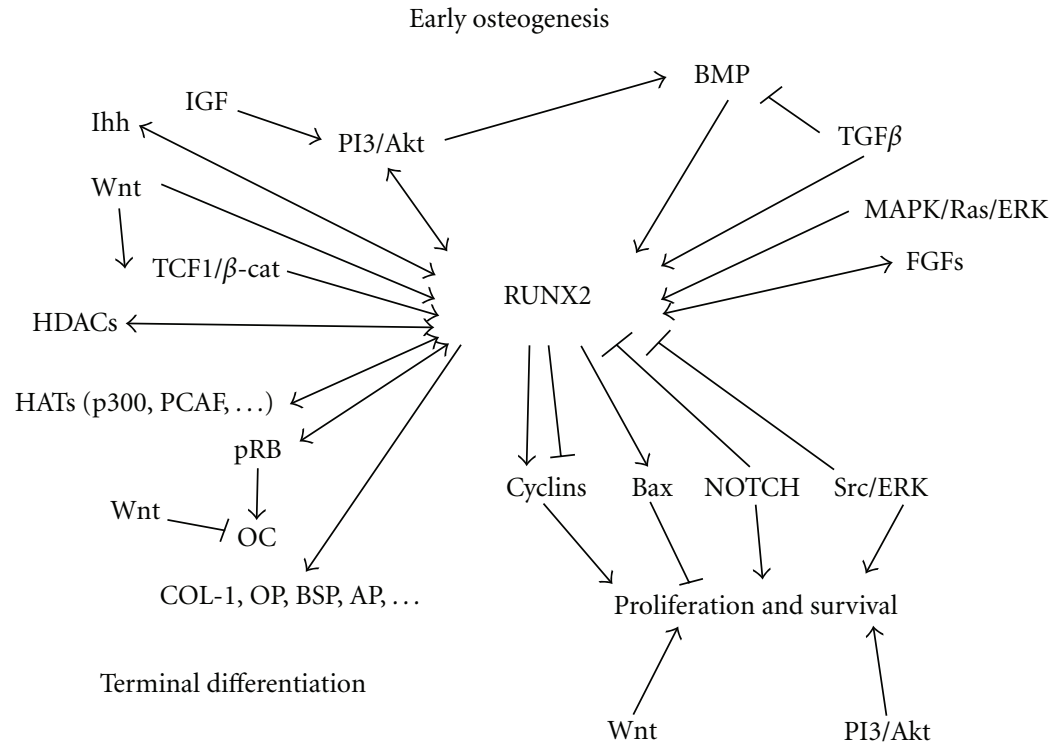

FIGURE 2: RUNX2 transcription and RUNX2 activity are influenced by many signaling molecules during osteoblast development. Summarised here, a large number of complex protein-protein interactions characterise RUNX2 activity, and transcription of RUNX2 and protein levels of the encoded product are influenced by a multitude of factors depending on the stage of osteoblast differentiation (see text for detailed descriptions). Arrows indicate protein-protein interactions and/or transcriptional upregulation whereas connections ending with a flat arrowhead indicate inhibitory effects.

On the other hand, expression of RUNX2 is reduced by $1,25-(\mathrm{OH})_{2}$-vitamin $\mathrm{D} 3$ (VD3) [83], peroxisome proliferation-activated receptor gamma $2(\operatorname{PPAR} \gamma 2)$ [84], and tumour necrosis factor alpha $(\mathrm{TNF} \alpha)$ at the transcriptional and posttranscriptional levels [85]. NKX3.2/BAPX1 is upregulated by SOX9 in terminal chondrogenesis to reduce expression of RUNX2 [86, 87]. Cyclic AMP signaling promotes proteasome-mediated degradation of RUNX2 [88], and RUNX2 activity is modulated by residue-specific phosphorylation [89], binding by inhibitory proteins such as coactivator activator (CoAA) [90], and acetylation of the protein [91].

\section{RUNX2 Signaling in Osteogenesis Has Potential for Deregulation in Oncogenesis}

RUNX2 regulates osteoblast lineage determination and expansion, osteoblast maturation, and terminal differentiation via a complex variety of pathways. Early osteoblast progenitor cells arise from pluripotent MSCs due to direct interactions of RUNX2 with broadly acting developmental pathways. Canonical Wnt factors and Hh family members are well known to inhibit adipogenic or chondrogenic differentiation of MSCs and to promote a preosteoblastic phenotype [92-94]. A number of relationships between RUNX2 and the canonical Wnt pathway have recently been shown to guide osteoblast commitment. In MSCs, RUNX2 forms a complex with lymphoid enhancer-binding factor 1 (LEF1), which is coactivated by betacatenin, to activate the fibroblast growth factor 18 (FGF18) gene [95], whose product inhibits chondrogenesis and supports osteogenesis [96].
The canonical Wnt pathway in particular is important throughout osteoblast differentiation. Without Wnt signaling, RUNX2-mediated transcriptional activation of the osterix (Osx1/SP7) gene in osteoprogenitors cannot lead to further commitment to the osteoblast lineage [97]. Following lineage commitment, RUNX2 promotes differentiation, and a particularly important early step following commitment is the interaction between RUNX2 and SMAD proteins induced by BMP and TGF $\beta$. In osteoprogenitors, BMP2 serves to induce osterix expression and promote osteoblast differentiation in a RUNX2-independent manner [98, 99], and in order for osteogenesis to approach completion, BMP/TGF $\beta$ signaling must be facilitated by the formation of the RUNX2-SMAD complex, which activates transcription of late osteoblast markers [100].

Proliferation and migration of committed osteoblasts precedes quiescence and terminal differentiation. Osteoblast proliferation and survival is promoted in large part by canonical Wnt signaling directly through LRP5 $[101,102]$ and indirectly via Src/ERK and PI3K/Akt [103]. Several studies have shown that RUNX2 attenuates osteoblast proliferation, and its protein levels are maximal during the G1 phase in which differentiation and growth occur. RUNX2 activity is maintained at high levels into the G0 phase if quiescence is induced, but is otherwise downregulated at the G1 to $S$ transition and in the subsequent $S, G 2$, and $M$ phases [24, 89, 104]. Mitosis sees residual RUNX2 localised in active nucleolar organising regions to repress transcription of ribosomal RNA genes [105]. RUNX2 may support epigenetic regulation of protein-encoding genes during mitosis [106], a mechanism referred to as "bookmarking" [107]. In vitro, contact inhibition or serum deprivation 
is associated with increased RUNX2 and cell-cycle exit, while RUNX2 deficiency induces increased growth potential [104]. Through activation by BMP/SMAD signaling, RUNX2 upregulates $B A X$ expression to induce apoptosis in studies of the osteosarcoma cell line SAOS-2 [108].

Though its role in cell growth inhibition is well established, RUNX2 also promotes cell proliferation and survival. The maximal levels of RUNX2 during G1 may actually be necessary to stimulate continued cell division $[24,109]$. RUNX2 represses transcription of p21/CDKN1A/WAF1/ CIP1, which encodes a cyclin-dependent kinase inhibitor that arrests cells in G1 [110], and it activates Gpr30 transcription and represses $R g s 2$ transcription to increase cellular response to mitogenic signaling through cyclic AMP and G-proteincoupled receptor signaling pathways [109]. In converse to the finding that RUNX2 upregulates $B A X$ expression in the SAOS-2 cell line [108], nitric oxide (NO) treatment of the MG-63 osteosarcoma cell line induces RUNX2mediated BCL2 expression, which promotes survival of the cells during oxidative stress [111]. NO signaling through cyclic guanosine $3^{\prime}, 5^{\prime}$-monophosphate (cGMP) may also cause site-specific phosphorylation of RUNX2 by protein kinase $\mathrm{G}(\mathrm{PKG})$, leading to upregulated transcription of the matrix metalloproteinase (MMP) gene MMP13 [112]. MMP13 is one of several members of the MMP family with important roles in cartilage degradation during endochondral ossification and later bone remodeling (reviewed in [113]).

Additionally, during bone development and remodeling, RUNX2 and PI3K-Akt mutually upregulate each other to enhance chemotactic osteoblast migration [114], which occurs along gradients of platelet-derived growth factor (PDGF), TGF $\beta$, and IGF [115-117]. Terminal osteoblast differentiation is accomplished through cell-cycle exit and complete expression of osteoblast phenotypic markers. RUNX2 induces higher levels of $\mathrm{p} 27^{K I P 1} / \mathrm{CDKN} 1 \mathrm{~B}$, which inhibits S-phase cyclin-dependent kinases to promote cellcycle exit and causes dephosphorylation of pRB [118]. Active, hypophosphorylated pRB is necessary for cell-cycle exit at this stage [119] and, through cooperation with the transcription factor HES1 [120], the hypophosphorylated form of pRB is bound by RUNX2. The RUNX2-pRB complex then coactivates transcription of genes encoding late markers of osteoblast differentiation, including osteocalcin [121]. Osteocalcin is also activated by RUNX2 in complex with histone acetyltransferases (HATs) p300 and p300/cyclic AMP receptor element-binding protein binding protein-associated factor (PCAF) [122], as well as monocytic leukemia zinc finger protein (MOZ) and MOZ-related factor (MORF) [123]. Other late osteoblast markers include alkaline phosphatase (AP), osteopontin (OP), bone sialoprotein (BSP), and collagen type I (COL-1), all of which require RUNX2SMAD signaling, induced by $\mathrm{BMP} / \mathrm{TGF} \beta$, to be expressed [100] (Figure 2).

Depending on the phosphorylation level of RUNX2 and the stage of differentiation, it also interacts with several corepressor proteins. Histone deacetylases (HDACs) 6 and 3 interact with RUNX2 to repress $p 21 / C D K N 1 A / W A F 1 / C I P 1$ and osteocalcin, thus regulating osteoblast development during proliferation and terminal differentiation [110, 124]. The mSin3a, TLE/Groucho, and Yes-associated protein (YAP) corepressors form complexes with RUNX2 and other HDAC proteins to repress expression of osteoblast-specific genes, particularly osteocalcin $[47,125,126]$, and HDAC4 induces transcriptional repression by binding RUNX2 to inhibit its intrinsic DNA-binding activity [127]. The transcriptional regulation and tissue-specific nature of RUNX2 activity thus depends a great deal on the proteins it forms multisubunit complexes with, and studies are ongoing to characterise the complex relationship between RUNX2 and the downstream factors that control osteoblast development.

\section{Potential Significance of RUNX2 in Osteosarcoma}

During development of normal bone, RUNX2 levels increase gradually after commitment of MSCs to the osteoblast lineage to maximal levels in early osteoblasts (Figure 3(a)). Several recent studies of osteosarcoma specimens have reported constitutively high protein levels of RUNX2. Although such studies of RUNX2 in clinical samples are rare, they are compelling in their findings. Andela et al. [128] published the earliest report we could find of RUNX2 immunoreactivity in osteosarcomas; the researchers tested 11 pathology specimens of the cancer and found RUNX2 immunopositivity in all of them. A comprehensive DNAmRNA-protein analysis of patient samples by Lu et al. [12] found mRNA overexpression of RUNX2 in 13 of 13 samples with genomic amplification in 8 of the 13 .

Three more recently published studies were successful in linking RUNX2 expression with measures of clinical course in patients with osteosarcoma. In a study of 22 osteosarcomas by our lab, mRNA overexpression of RUNX2 was on average 3.3 times higher in tumours that had responded poorly ( $<90 \%$ necrosis) to neoadjuvant chemotherapy relative to tumours with good response ( $>90 \%$ necrosis). Compared to normal human osteoblasts, every tumour specimen had higher RUNX2 mRNA expression [23]. Similarly, Won and colleagues observed low RUNX2 expression in $60 \%$ (29/48) of cores and high RUNX2 expression in 23\% (11/48) of cores. In this study, high RUNX2 expression was significantly correlated with metastasis and predicted a trend towards lower survival [131]. Another study analysed the comparative immunoreactivity of RUNX2 in different types of patient samples, finding positive staining in $60 \%(12 / 20)$ of biopsy samples and $73 \%(8 / 11)$ of metastatic tumours. Interestingly, this same study found only $16 \%(4 / 25)$ of postchemotherapeutic resections were positive for RUNX2 staining [132]. Thus, the results of these recent studies are suggestive of predictive value of RUNX2.

The function of RUNX2 in osteosarcoma has not yet been identified, but given the complex functionality of RUNX2 in developing osteoblasts, deregulation of the protein could act during osteosarcoma pathogenesis. Significantly, cell cycledependent regulation of RUNX2 is absent in the cell line 


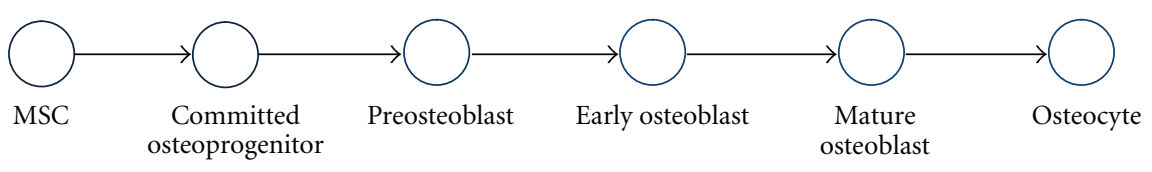

RUNX2 protein levels

(a) Normal osteogenesis

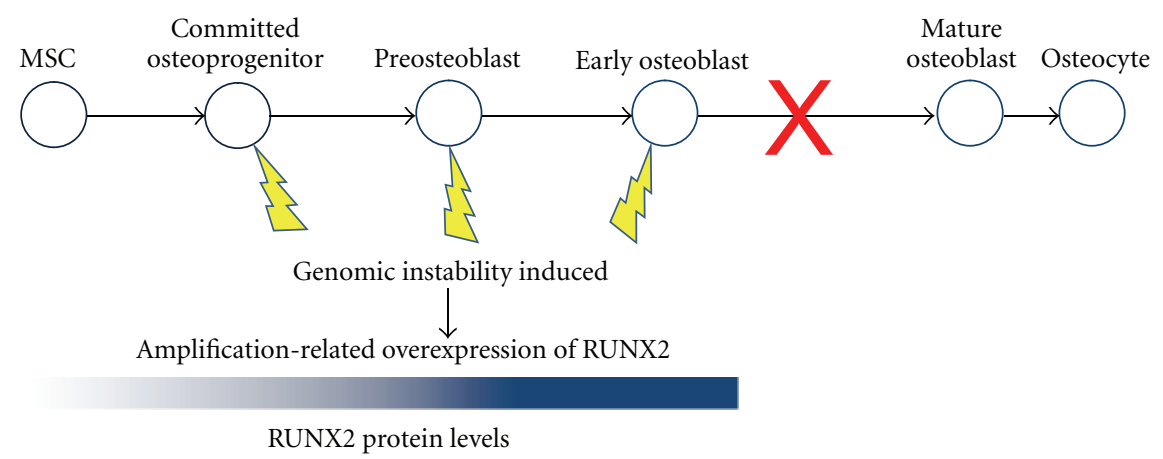

(b) Osteosarcoma development

FIGURE 3: Osteoblast differentiation and RUNX2 protein levels. (a) In normal osteogenesis initiating in MSCs, overall RUNX2 protein levels are maximal in preosteoblasts and early mature osteoblasts, after gradually increasing during commitment. Overall RUNX2 levels are very low in mature osteoblasts and osteocytes [129]. RUNX2 activity and levels are modulated according to cell-cycle stage by posttranslational modification and transcriptional regulation of RUNX2, respectively. (b) In osteosarcoma development, genomic instability is induced (lightning bolts), for example by inactivation of $\mathrm{pRB}$ or $\mathrm{p} 53$, in cells committed to the osteoid lineage. Extensive rearrangements occur, with amplification of chromosome 6p12-p21 being a frequent early event in many cases. Amplification-related overexpression of RUNX2 could result, leading to high levels of RUNX2 protein throughout the cell cycle and disrupted regulation of RUNX2 activity. Consequently, osteoblast differentiation is halted before or during maturation and characteristics of immature osteoblast-like cells are retained in the resulting osteosarcoma. Adapted from [130].

SAOS-2 and the protein is maintained at high levels throughout the cell cycle, particularly during the G1 to $S$ transition when it is normally downregulated [24]. Previously published studies have shown that RUNX2 interacts specifically with hypophosphorylated pRB during initiation of cellcycle withdrawal during terminal osteoblast differentiation $[118,121,133]$. Inactivation of $\mathrm{pRB}$ is very common to a small subset of tumours including osteosarcoma [134], and in particular, $50 \%-70 \%$ of osteosarcomas do not have functional pRB [6]. In the absence of pRB, RUNX2-pRBinduced cell-cycle exit would not be possible, and this could lead to uninhibited proliferation of osteoprogenitor cells, as well as increased genomic instability [135].

Apart from the pRB-RUNX2 connection, there is evidence indicating that normal RUNX2 function in bone is linked to the p53-MDM2 pathway [136]. The p53 pathway is perturbed in Li-Fraumeni patients, and there is increased osteosarcoma incidence in Li-Fraumeni families $[8,9]$. Furthermore, bone-specific knockout of p53 is dominant over loss of pRB in the predisposition to osteosarcoma in mouse models [119, 137]. RUNX2-dependent osteoblastic differentiation is compromised when the p53-MDM2 pathway is genetically perturbed, and loss of p53 function increases the differentiation-related accumulation of RUNX2 [138]. In contrast to primary or immortalised osteoblasts, which normally have low RUNX2 levels, loss of p53 correlates with elevated RUNX2 protein levels in several growth factorindependent osteosarcoma cell lines [26, 27]. Hence, it is conceivable that loss of p53 function in osteosarcomas is permissive for or even contributes to the elevated protein levels that are observed in osteosarcoma patient samples with 6p12-6p21 gene amplifications [11-17, 22].

Cell cycle-dependent activity of RUNX2 is regulated by cyclin-dependent kinase- (CDK-) mediated phosphorylation [89], and the $\mathrm{p} 27^{K I P 1} / \mathrm{CDKN} 1 \mathrm{~B}$ cyclin-dependent kinase inhibitor is also required for terminal differentiation and cell-cycle exit by interaction with RUNX2. Protein levels of $\mathrm{p} 27^{K I P 1}$ are reduced in the undifferentiated subtype of osteosarcoma [118]. Our own aCGH analysis of 15 osteosarcoma patient samples detected loss of CDKN1B in nine of 15 samples (our unpublished data). RUNX2 signaling in the absence of the tumour suppressors pRB and p2 $7^{K I P 1}$ would, therefore, be limited in its capacity to halt proliferation and induce osteoblast maturation. Similarly, reduced expression of the $\mathrm{p} 21^{C I P 1} / \mathrm{CDKN} 1 \mathrm{~A}$ cyclin-dependent kinase inhibitor may occur as a result of elevated RUNX2 protein levels (which transcriptionally represses the $\mathrm{p} 21^{\mathrm{CIP1}} / \mathrm{CDKN} 1 \mathrm{~A}$ gene) [110] and the concurrent loss of p53 (which is the major transactivator of $\left.21^{C I P 1} / C D K N 1 A\right)[139]$. Reduced p21 ${ }^{C I P 1}$ levels would prevent cell-growth arrest and DNA repair following DNA damage during chemotherapy and radiation of osteosarcomas in the clinic. 
Clearly, the prodifferentiation and tumour suppressor function of RUNX2 has potential for deregulation, in that MSCs committed to the osteoblast lineage could be stalled in their differentiation before development of the mature osteoblast phenotype. Recently, it was found that Notch1 inhibits RUNX2 directly by binding it [140] and indirectly by upregulating cyclin D1-dependent kinase CDK4, which ubiquitinates RUNX2 [141]. An association has been found between upregulated Notch signaling and lung metastatic potential in osteosarcoma cell lines [142], but no functional studies have yet linked inactivation of RUNX2 directly to osteosarcoma metastasis.

Contrary to the tumour suppressor-like behaviour of RUNX2 that has been described by previously published studies of the protein $[24,104,143]$, several recent studies have identified RUNX2 as potentially having a direct role in promoting neoplasia, particularly in prostate and breast cancers. To begin with, RUNX2 is highly integrated, often through reciprocal activation pathways, with PI3K/Akt, Wnt, BMP/TGF $\beta$, MAPK/ERK, and Notch signaling, all of which can be activated in osteosarcomas and other tumours [144-147]. A comprehensive study by Akech et al. [148] demonstrated that overexpression of RUNX2 in prostate cancer cells inoculated into bone led to activation of genes necessary for osteolytic disease, $\mathrm{PTH}$-related protein $(\mathrm{PTHr} P$ ) and interleukin 8 (IL8). Both PTHrP and RUNX2 activate expression of receptor activator of nuclear factor- $\kappa \mathrm{B}$ ligand (RANKL), which stimulates osteoclast formation and subsequent bone resorption $[149,150]$ whereas IL8 promotes osteolysis through osteoclast formation independent of RANKL [151]. Interestingly, osteosarcomas are frequently mixed osteolytic and osteoblastic tumours [1], and RANK/RANKL is overexpressed in subsets of the tumours [152]. Akech et al. [148] also detected that prostate cancer overexpression of RUNX2 activated genes necessary for metastasis and invasion (MMP2, MMP9, MMP13), angiogenesis (VEGF, osteopontin), and survival (survivin). These findings are consistent with other studies of the metastasis-promoting role of RUNX2 in prostate cancer cell lines [153-155] and metastatic patient specimens [156]. The results support similar observations of the requirement for RUNX2 expression in metastatic breast cancer-associated osteolytic disease [154, 157, 158].

RUNX2 appears to have dual roles as a tumour suppressor (described above) and as an oncoprotein, depending on its cellular levels and context, and its regulation. In Tcell lymphomas, overexpression of RUNX2 and the MYC oncogene leads to cooperation between the encoded proteins that maintains survival and proliferation in the cancer cells [159]. In pituitary tumours, RUNX2 upregulates the anoikis suppressor galectin-3 (LGALS3) [160], which may also facilitate osteosarcoma metastasis [161]. The role of the protein in bone tumourigenesis is complicated, however, by incomplete knowledge of consequences of its deregulation in osteoblasts. High levels of RUNX2 inhibit apoptosis of osteoblasts in the presence of parathyroid hormone $(\mathrm{PTH})$, which stimulates bone turnover [162]. Interaction between overexpressed RUNX2 and the protein product of proto-oncogene FOS, whose overexpression in mice led to development of the first osteosarcoma mouse model [163], upregulates transcription of the metastasis-associated gene MMP13 via transcription factor AP-1 [164] and has potential for other roles in oncogenesis [165].

\section{Conclusions and Future Directions}

The dual roles of RUNX2 must be tightly regulated during osteoblast differentiation for normal bone development. Other studies have noted the resemblance of some osteosarcomas to committed osteoprogenitor cells that have undergone cell-cycle deregulation and have been blocked in their differentiation towards osteocytes $[118,130,166-$ 168]. Additionally, there is a range of differentiation status among osteosarcomas [1] that is reflected in the welldescribed osteosarcoma cell lines [26, 118, 169-173] and has been demonstrated in the development of mouse models of the disease $[119,137]$. Disruption of RUNX2 signaling by high levels of the protein in osteoblast progenitor cells (Figure 3(b)) could significantly interrupt osteoblast differentiation and cell-cycle regulation.

It is possible that RUNX2 overexpression resulting from gain and amplification of chromosome 6p12-p21 is a causative factor in osteosarcoma pathogenesis, because it is consistently overexpressed in patient specimens $[12,128$, $131,132]$, because of its oncogenic potential, and because of the potential for its tumour suppressor functions to be deregulated. Its overexpression at the protein level is likely driven by its genetic amplification at the DNA level [12, 174], our unpublished data] and facilitated by disrupted degradation $[27,132]$. The instability of chromosome 6p12p21 that leads to RUNX2 gain and amplification has been demonstrated by many studies of patient samples, including biopsies [11-13,15,17], and thus it is probably an early event in osteosarcoma pathogenesis.

The complexity of osteosarcoma has continually posed a serious problem to understanding the etiology of the disease and identifying prognostic or predictive factors, or therapeutic targets. RUNX2 has potential to be predictive of response to the standard chemotherapy regimen according to studies by our lab, but further work to discover its cancerspecific function is needed. Additionally, larger cohorts of patients are necessary to definitively link RUNX2 level to treatment response in osteosarcoma tumours. In conclusion, the frequency of RUNX2 gain and elevated RUNX2 in osteosarcoma patient specimens as well as its documented functions lends to its possible value as a predictive factor and as a therapeutic target.

\section{Acknowledgments}

This work was supported by the Canadian Cancer Society (Grant no. 16215) and the National Institutes of Health (NIH) (R01 AR049069 to A. J. van Wijnen and P01 CA082834 to G. S. Stein). J. W. Martin was funded in part by the Queen's University Terry Fox Foundation Training Program in Transdisciplinary Cancer Research in partnership with the Canadian Institutes of Health Research (CIHR). 


\section{References}

[1] A. K. Raymond, A. G. Ayala, and S. Knuutila, "Conventional osteosarcoma," in Pathology and Genetics of Tumours of Soft Tissue and Bone, Fletcher CDM, K. K. Unni and F. Mertens, Eds., pp. 264-270, IARC Press, Lyon, France, 2002.

[2] S. S. Bielack, B. Kempf-Bielack, G. Delling et al., "Prognostic factors in high-grade osteosarcoma of the extremities or trunk: an analysis of 1,702 patients treated on neoadjuvant cooperative osteosarcoma study group protocols," Journal of Clinical Oncology, vol. 20, no. 3, pp. 776-790, 2002.

[3] A. Longhi, C. Errani, M. De Paolis, M. Mercuri, and G. Bacci, "Primary bone osteosarcoma in the pediatric age: state of the art," Cancer Treatment Reviews, vol. 32, no. 6, pp. 423-436, 2006.

[4] N. Jaffe, "Osteosarcoma: review of the past, impact on the future. The American experience," Cancer Treatment and Research, vol. 152, pp. 239-262, 2009.

[5] G. Bacci, S. Ferrari, A. Longhi et al., "Pattern of relapse in patients with osteosarcoma of the extremities treated with neoadjuvant chemotherapy," European Journal of Cancer, vol. 37, no. 1, pp. 32-38, 2001.

[6] M. Kansara and D. M. Thomas, "Molecular pathogenesis of osteosarcoma," DNA and Cell Biology, vol. 26, no. 1, pp. 1-18, 2007.

[7] M. F. Hansen, A. Koufos, and B. L. Gallie, "Osteosarcoma and retinoblastoma: a shared chromosomal mechanism revealing recessive predisposition," Proceedings of the National Academy of Sciences of the United States of America, vol. 82, no. 18, pp. 6216-6220, 1985.

[8] B. Fuchs and D. J. Pritchard, "Etiology of osteosarcoma," Clinical Orthopaedics and Related Research, no. 397, pp. 4052, 2002.

[9] D. Malkin, F. P. Li, L. C. Strong et al., "Germ line p53 mutations in a familial syndrome of breast cancer, sarcomas, and other neoplasms," Science, vol. 250, no. 4985, pp. 1233 1238, 1990.

[10] G. Maire, M. Yoshimoto, S. Chilton-MacNeill, P. S. Thorner, M. Zielenska, and J. A. Squire, "Recurrent RECQL4 imbalance and increased gene expression levels are associated with structural chromosomal instability in sporadic osteosarcoma," Neoplasia, vol. 11, no. 3, pp. 260-268, 2009.

[11] C. C. Lau, C. P. Harris, X.-Y. Lu et al., "Frequent amplification and rearrangement of chromosomal bands 6p12-p21 and 17 p11.2 in osteosarcoma," Genes Chromosomes and Cancer, vol. 39, no. 1, pp. 11-21, 2004.

[12] X.-Y. Lu, Y. Lu, Y.-J. Zhao et al., "Cell cycle regulator gene CDC5L, a potential target for 6p12-p21 amplicon in osteosarcoma," Molecular Cancer Research, vol. 6, no. 6, pp. 937-946, 2008.

[13] T.-K. Man, X.-Y. Lu, K. Jaeweon et al., "Genome-wide array comparative genomic hybridization analysis reveals distinct amplifications in osteosarcoma," BMC Cancer, vol. 4, article 45, 2004.

[14] J. Smida, D. Baumhoer, M. Rosemann et al., "Genomic alterations and allelic imbalances are strong prognostic predictors in osteosarcoma," Clinical Cancer Research, vol. 16, no. 16, pp. 4256-4267, 2010.

[15] J. A. Squire, J. Pei, P. Marrano et al., "High-resolution mapping of amplifications and deletions in pediatric osteosarcoma by use of CGH analysis of cDNA microarrays," Genes Chromosomes and Cancer, vol. 38, no. 3, pp. 215-225, 2003.
[16] M. Zielenska, J. Bayani, A. Pandita et al., "Comparative genomic hybridization analysis identifies gains of 1 p35 p36 and chromosome 19 in osteosarcoma," Cancer Genetics and Cytogenetics, vol. 130, no. 1, pp. 14-21, 2001.

[17] M. Zielenska, P. Marrano, P. Thorner et al., "High-resolution cDNA microarray CGH mapping of genomic imbalances in osteosarcoma using formalin-fixed paraffin-embedded tissue," Cytogenetic and Genome Research, vol. 107, no. 1-2, pp. 77-82, 2004.

[18] S. Selvarajah, M. Yoshimoto, O. Ludkovski et al., "Genomic signatures of chromosomal instability and osteosarcoma progression detected by high resolution array CGH and interphase FISH," Cytogenetic and Genome Research, vol. 122, no. 1, pp. 5-15, 2008.

[19] S. Selvarajah, M. Yoshimoto, G. Maire et al., "Identification of cryptic microaberrations in osteosarcoma by high-definition oligonucleotide array comparative genomic hybridization," Cancer Genetics and Cytogenetics, vol. 179, no. 1, pp. 52-61, 2007.

[20] S. Selvarajah, M. Yoshimoto, P. C. Park et al., "The breakagefusion-bridge (BFB) cycle as a mechanism for generating genetic heterogeneity in osteosarcoma," Chromosoma, vol. 115, no. 6, pp. 459-467, 2006.

[21] B. Sadikovic, M. Yoshimoto, K. Al-Romaih, G. Maire, M. Zielenska, and J. A. Squire, "In vitro analysis of integrated global high-resolution DNA methylation profiling with genomic imbalance and gene expression in osteosarcoma," PLoS ONE, vol. 3, no. 7, Article ID e2834, 2008.

[22] A. Forus, D. O. Weghuis, D. Smeets, O. Fodstad, O. Myklebost, and A. G. Van Kessel, "Comparative genomic hybridization analysis of human sarcomas: II. Identification of novel amplicons at $6 \mathrm{p}$ and $17 \mathrm{p}$ in osteosarcomas," Genes Chromosomes and Cancer, vol. 14, no. 1, pp. 15-21, 1995.

[23] B. Sadikovic, P. Thorner, S. Chilton-MacNeill et al., "Expression analysis of genes associated with human osteosarcoma tumors shows correlation of RUNX2 overexpression with poor response to chemotherapy," BMC Cancer, vol. 10, article 202, 2010.

[24] M. Galindo, J. Pratap, D. W. Young et al., "The bone-specific expression of Runx2 oscillates during the cell cycle to support a G1-related antiproliferative function in osteoblasts," Journal of Biological Chemistry, vol. 280, no. 21, pp. 2027420285, 2005.

[25] S. S. Nathan, B. P. Pereira, Y.-F. Zhou et al., "Elevated expression of Runx2 as a key parameter in the etiology of osteosarcoma," Molecular Biology Reports, vol. 36, no. 1, pp. 153-158, 2009.

[26] B. P. Pereira, Y. Zhou, A. Gupta et al., "Runx2, p53, and pRB status as diagnostic parameters for deregulation of osteoblast growth and differentiation in a new pre-chemotherapeutic osteosarcoma cell line (OS1)," Journal of Cellular Physiology, vol. 221, no. 3, pp. 778-788, 2009.

[27] I. A. San Martin, N. Varela, M. Gaete et al., "Impaired cell cycle regulation of the osteoblast-related heterodimeric transcription factor Runx2-Cbfbeta in osteosarcoma cells," Journal of Cellular Physiology, vol. 221, no. 3, pp. 560-571, 2009.

[28] D. Levanon, V. Negreanu, Y. Bernstein, I. Bar-Am, L. Avivi, and Y. Groner, "AML1, AML2, and AML3, the human members of the runt domain gene-family: cDNA structure, expression, and chromosomal localization," Genomics, vol. 23, no. 2, pp. 425-432, 1994. 
[29] A. J. van Wijnen, G. S. Stein, J. P. Gergen et al., "Nomenclature for Runt-related (RUNX) proteins," Oncogene, vol. 23, no. 24, pp. 4209-4210, 2004.

[30] H. Kagoshima, K. Shigesada, and Y. Kohara, "RUNX regulates stem cell proliferation and differentiation: insights from studies of C. elegans," Journal of Cellular Biochemistry, vol. 100, no. 5, pp. 1119-1130, 2007.

[31] B. Lutterbach and S. W. Hiebert, "Role of the transcription factor AML-1 in acute leukemia and hematopoietic differentiation," Gene, vol. 245, no. 2, pp. 223-235, 2000.

[32] T. Okuda, J. Van Deursen, S. W. Hiebert, G. Grosveld, and J. R. Downing, "AML1, the target of multiple chromosomal translocations in human leukemia, is essential for normal fetal liver hematopoiesis," Cell, vol. 84, no. 2, pp. 321-330, 1996.

[33] Q. Wang, T. Stacy, M. Binder, M. Marín-Padilla, A. H. Sharpe, and N. A. Speck, "Disruption of the Cbfa2 gene causes necrosis and hemorrhaging in the central nervous system and blocks definitive hematopoiesis," Proceedings of the National Academy of Sciences of the United States of America, vol. 93, no. 8, pp. 3444-3449, 1996.

[34] K.-I. Inoue, K. Ito, M. Osato, B. Lee, S.-C. Bae, and Y. Ito, "The transcription factor Runx3 represses the neurotrophin receptor TrkB during lineage commitment of dorsal root ganglion neurons," Journal of Biological Chemistry, vol. 282, no. 33, pp. 24175-24184, 2007.

[35] K.-I. Inoue, S. Ozaki, T. Shiga et al., "Runx3 controls the axonal projection of proprioceptive dorsal root ganglion neurons," Nature Neuroscience, vol. 5, no. 10, pp. 946-954, 2002.

[36] Q.-L. Li, K. Ito, C. Sakakura et al., "Causal relationship between the loss of RUNX3 expression and gastric cancer," Cell, vol. 109, no. 1, pp. 113-124, 2002.

[37] K. Ito, Q. Liu, M. Salto-Tellez et al., "RUNX3, a novel tumor suppressor, is frequently inactivated in gastric cancer by protein mislocalization," Cancer Research, vol. 65, no. 17, pp. 7743-7750, 2005.

[38] T. Komori, H. Yagi, S. Nomura et al., "Targeted disruption of Cbfal results in a complete lack of bone formation owing to maturational arrest of osteoblasts," Cell, vol. 89, no. 5, pp. 755-764, 1997.

[39] F. Otto, A. P. Thornell, T. Crompton et al., "Cbfa1, a candidate gene for cleidocranial dysplasia syndrome, is essential for osteoblast differentiation and bone development," Cell, vol. 89, no. 5, pp. 765-771, 1997.

[40] T. Komori, "Regulation of bone development and extracellular matrix protein genes by RUNX2," Cell and Tissue Research, vol. 339, no. 1, pp. 189-195, 2010.

[41] V. Geoffroy, D. A. Corral, L. Zhou, B. Lee, and G. Karsenty, "Genomic organization, expression of the human CBFA1 gene, and evidence for an alternative splicing event affecting protein function," Mammalian Genome, vol. 9, no. 1, pp. 5457, 1998.

[42] N. Makita, M. Suzuki, S. Asami et al., "Two of four alternatively spliced isoforms of RUNX2 control osteocalcin gene expression in human osteoblast cells," Gene, vol. 413, no. 1-2, pp. 8-17, 2008.

[43] Z. S. Xiao, R. Thomas, T. K. Hinson, and L. D. Quarles, "Genomic structure and isoform expression of the mouse, rat and human Cbfa1/Osf2 transcription factor," Gene, vol. 214, no. 1-2, pp. 187-197, 1998.

[44] A. Terry, A. Kilbey, F. Vaillant et al., "Conservation and expression of an alternative $3^{\prime}$ exon of Runx2 encoding a novel proline-rich C-terminal domain," Gene, vol. 336, no. 1, pp. 115-125, 2004.

[45] J. B. Lian, A. Javed, S. K. Zaidi et al., "Regulatory controls for osteoblast growth and differentiation: role of Runx/Cbfa/AML factors," Critical Reviews in Eukaryotic Gene Expression, vol. 14, no. 1-2, pp. 1-41, 2004.

[46] K. Thirunavukkarasu, M. Mahajan, K. W. McLarren, S. Stifani, and G. Karsenty, "Two domains unique to osteoblastspecific transcription factor Osf2/Cbfal contribute to its transactivation function and its inability to heterodimerize with Cbf $\beta$," Molecular and Cellular Biology, vol. 18, no. 7, pp. 4197-4208, 1998.

[47] A. Javed, B. Guo, S. Hiebert et al., "Groucho/TLE/R-esp proteins associate with the nuclear matrix and repress RUNX $(\mathrm{CBF} \alpha / \mathrm{AML} / \mathrm{PEBP} 2 \alpha)$ dependent activation of tissue-specific gene transcription," Journal of Cell Science, vol. 113, no. 12, pp. 2221-2231, 2000.

[48] D. Levanon, R. E. Goldstein, Y. Bernstein et al., "Transcriptional repression by AML1 and LEF-1 is mediated by the TLE/Groucho corepressors," Proceedings of the National Academy of Sciences of the United States of America, vol. 95, no. 20, pp. 11590-11595, 1998.

[49] H. Drissi, Q. Luc, R. Shakoori et al., "Transcriptional autoregulation of the bone related CBFA1/RUNX2 gene," Journal of Cellular Physiology, vol. 184, no. 3, pp. 341-350, 2000.

[50] M. Stock and F. Otto, "Control of RUNX2 isoform expression: the role of promoters and enhancers," Journal of Cellular Biochemistry, vol. 95, no. 3, pp. 506-517, 2005.

[51] H. Kagoshima, K. Shigesada, M. Satake et al., "The Runt domain identifies a new family of heteromeric transcriptional regulators," Trends in Genetics, vol. 9, no. 10, pp. 338$341,1993$.

[52] J. Canon and U. Banerjee, "Runt and Lozenge function in Drosophila development," Seminars in Cell and Developmental Biology, vol. 11, no. 5, pp. 327-336, 2000.

[53] E. Ogawa, M. Maruyama, H. Kagoshima et al., "PEBP2/PEA2 represents a family of transcription factors homologous to the products of the Drosophila runt gene and the human AML1 gene," Proceedings of the National Academy of Sciences of the United States of America, vol. 90, no. 14, pp. 6859-6863, 1993.

[54] J. Miller, A. Horner, T. Stacy et al., "The core-binding factor $\beta$ subunit is required for bone formation and hematopoietic maturation," Nature Genetics, vol. 32, no. 4, pp. 645-649, 2002.

[55] E. Ogawa, M. Inuzuka, M. Maruyama et al., "Molecular cloning and characterization of PEBP $2 \beta$, the heterodimeric partner of a novel Drosophila runt-related DNA binding protein PEBP2 $\alpha$," Virology, vol. 194, no. 1, pp. 314-331, 1993.

[56] M. Satake, S. Nomura, Y. Yamaguchi-Iwai et al., "Expression of the Runt domain-encoding PEBP $2 \alpha$ genes in T cells during thymic development," Molecular and Cellular Biology, vol. 15, no. 3, pp. 1662-1670, 1995.

[57] C. J. Lengner, H. Drissi, J.-Y. Choi et al., "Activation of the bone-related Runx2/Cbfal promoter in mesenchymal condensations and developing chondrocytes of the axial skeleton," Mechanisms of Development, vol. 114, no. 1-2, pp. 167-170, 2002.

[58] S. Mundlos, J. B. Mulliken, D. L. Abramson, M. L. Warman, J. H. M. Knoll, and B. R. Olsen, "Genetic mapping of cleidocranial dysplasia and evidence of a microdeletion in one family," Human Molecular Genetics, vol. 4, no. 1, pp. 7175, 1995. 
[59] R. S. Ramesar, J. Greenberg, R. Martin et al., "Mapping of the gene for cleidocranial dysplasia in the historical Cape Town (Arnold) kindred and evidence for locus homogeneity," Journal of Medical Genetics, vol. 33, no. 6, pp. 511-514, 1996.

[60] S. Mundlos, F. Otto, C. Mundlos et al., "Mutations involving the transcription factor CBFA1 cause cleidocranial dysplasia," Cell, vol. 89, no. 5, pp. 773-779, 1997.

[61] I. Quack, B. Vonderstrass, M. Stock et al., "Mutation analysis of core binding factor A1 in patients with cleidocranial dysplasia," American Journal of Human Genetics, vol. 65, no. 5, pp. 1268-1278, 1999.

[62] J.-Y. Choi, J. Pratap, A. Javed et al., "Subnuclear targeting of Runx/CBFa/AML factors is essential for tissue-specific differentiation during embryonic development," Proceedings of the National Academy of Sciences of the United States of America, vol. 98, no. 15, pp. 8650-8655, 2001.

[63] Y. Lou, A. Javed, S. Hussain et al., "A Runx2 threshold for the cleidocranial dysplasia phenotype," Human Molecular Genetics, vol. 18, no. 3, pp. 556-568, 2009.

[64] C. Banerjee, S. W. Hiebert, J. L. Stein, J. B. Lian, and G. S. Stein, "An AML-1 consensus sequence binds an osteoblast-specific complex and transcriptionally activates the osteocalcin gene," Proceedings of the National Academy of Sciences of the United States of America, vol. 93, no. 10, pp. 4968-4973, 1996.

[65] H. L. Merriman, A. J. Van Wijnen, S. Hiebert et al., "The tissue-specific nuclear matrix protein, NMP-2, is a member of the AML/CBF/PEBP2/runt domain transcription factor family: interactions with the osteocalcin gene promoter," Biochemistry, vol. 34, no. 40, pp. 13125-13132, 1995.

[66] G. S. Stein, J. B. Lian, A. J. van Wijnen et al., "Runx2 control of organization, assembly and activity of the regulatory machinery for skeletal gene expression," Oncogene, vol. 23, no. 24, pp. 4315-4329, 2004.

[67] V. Geoffroy, M. Kneissel, B. Fournier, A. Boyde, and P. Matthias, "High bone resorption in adult aging transgenic mice overexpressing Cbfa1/Runx2 in cells of the osteoblastic lineage," Molecular and Cellular Biology, vol. 22, no. 17, pp. 6222-6233, 2002.

[68] S. Takeda, J.-P. Bonnamy, M. J. Owen, P. Ducy, and G. Karsenty, "Continuous expression of Cbfal in nonhypertrophic chondrocytes uncovers its ability to induce hypertrophic chondrocyte differentiation and partially rescues Cbfa1-deficient mice," Genes and Development, vol. 15, no. 4, pp. 467-481, 2001.

[69] C. A. Yoshida and T. Komori, "Role of Runx proteins in chondrogenesis," Critical Reviews in Eukaryotic Gene Expression, vol. 15, no. 3, pp. 243-254, 2005.

[70] G. Zhou, Q. Zheng, F. Engin et al., "Dominance of SOX9 function over RUNX2 during skeletogenesis," Proceedings of the National Academy of Sciences of the United States of America, vol. 103, no. 50, pp. 19004-19009, 2006.

[71] F. Long, U.-I. Chung, S. Ohba, J. McMahon, H. M. Kronenberg, and A. P. McMahon, "Ihh signaling is directly required for the osteoblast lineage in the endochondral skeleton," Development, vol. 131, no. 6, pp. 1309-1318, 2004.

[72] S. J. Rodda and A. P. McMahon, "Distinct roles for Hedgehog and caronical Wnt signaling in specification, differentiation and maintenance of osteoblast progenitors," Development, vol. 133, no. 16, pp. 3231-3244, 2006.

[73] C. A. Yoshida, H. Yamamoto, T. Fujita et al., "Runx2 and Runx3 are essential for chondrocyte maturation, and Runx2 regulates limb growth through induction of Indian hedgehog," Genes and Development, vol. 18, no. 8, pp. 952963, 2004.

[74] A. Mukherjee, E. M. Wilson, and P. Rotwein, "Selective signaling by Akt 2 promotes bone morphogenetic protein 2mediated osteoblast differentiation," Molecular and Cellular Biology, vol. 30, no. 4, pp. 1018-1027, 2010.

[75] L. Ling, C. Dombrowski, K. M. Foong et al., "Synergism between Wnt3a and heparin enhances osteogenesis via a phosphoinositide 3-kinase/Akt/RUNX2 pathway," Journal of Biological Chemistry, vol. 285, no. 34, pp. 26233-26244, 2010.

[76] T. Gaur, C. J. Lengner, H. Hovhannisyan et al., "Canonical WNT signaling promotes osteogenesis by directly stimulating Runx2 gene expression," Journal of Biological Chemistry, vol. 280, no. 39, pp. 33132-33140, 2005.

[77] T. P. Hill, D. Später, M. M. Taketo, W. Birchmeier, and C. Hartmann, "Canonical Wnt/ $\beta$-catenin signaling prevents osteoblasts from differentiating into chondrocytes," Developmental Cell, vol. 8, no. 5, pp. 727-738, 2005.

[78] Y. Zhang, M. Q. Hassan, R.-L. Xie et al., "Co-stimulation of the bone-related Runx2 P1 promoter in mesenchymal cells by SP1 and ETS transcription factors at polymorphic purine-rich DNA sequences (Y-repeats)," Journal of Biological Chemistry, vol. 284, no. 5, pp. 3125-3135, 2009.

[79] M. Q. Hassan, R. S. Tare, S. H. Lee et al., "BMP2 commitment to the osteogenic lineage involves activation of Runx2 by DLX3 and a homeodomain transcriptional network," Journal of Biological Chemistry, vol. 281, no. 52, pp. 40515-40526, 2006.

[80] T. Kanno, T. Takahashi, T. Tsujisawa, W. Ariyoshi, and T. Nishihara, "Mechanical stress-mediated Runx2 activation is dependent on Ras/ERK1/2 MAPK signaling in osteoblasts," Journal of Cellular Biochemistry, vol. 101, no. 5, pp. 12661277, 2007.

[81] P. G. Ziros, A.-P. R. Gil, T. Georgakopoulos et al., "The bone-specific transcriptional regulator $\mathrm{Cbfal}$ is a target of mechanical signals in osteoblastic cells," Journal of Biological Chemistry, vol. 277, no. 26, pp. 23934-23941, 2002.

[82] H.-J. Kim, J.-H. Kim, S.-C. Bae, J.-Y. Choi, H.-J. Kim, and H.-M. Ryoo, "The protein kinase C pathway plays a central role in the fibroblast growth factor-stimulated expression and transactivation activity of Runx2," Journal of Biological Chemistry, vol. 278, no. 1, pp. 319-326, 2003.

[83] H. Drissi, A. Pouliot, C. Koolloos et al., " $1,25-(\mathrm{OH})_{2}-$ vitamin $\mathrm{D}_{3}$ suppresses the bone-related Runx2/Cbfa1 gene promoter," Experimental Cell Research, vol. 274, no. 2, pp. 323-333, 2002.

[84] B. Lecka-Czernik, I. Gubrij, E. J. Moerman et al., "Inhibition of Osf2/Cbfa 1 expression and terminal osteoblast differentiation by PPAR 2 2," Journal of Cellular Biochemistry, vol. 74, no. 3, pp. 357-371, 1999.

[85] L. Gilbert, X. He, P. Farmer et al., "Expression of the osteoblast differentiation factor RUNX2 (Cbfa1/AML3/ Pebp $2 \alpha \mathrm{A}$ ) is inhibited by tumor necrosis factor- $\alpha$," Journal of Biological Chemistry, vol. 277, no. 4, pp. 2695-2701, 2002.

[86] S. Yamashita, M. Andoh, H. Ueno-Kudoh, T. Sato, S. Miyaki, and H. Asahara, "Sox9 directly promotes Bapx1 gene expression to repress Runx2 in chondrocytes," Experimental Cell Research, vol. 315, no. 13, pp. 2231-2240, 2009.

[87] C. J. Lengner, M. Q. Hassan, R. W. Serra et al., "Nkx3.2mediated repression of Runx2 promotes chondrogenic differentiation," Journal of Biological Chemistry, vol. 280, no. 16, pp. 15872-15879, 2005. 
[88] Y. Tintutt, F. Parhami, V. Le, G. Karsenty, and L. L. Demer, "Inhibition of osteoblast-specific transcription factor Cbfal by the cAMP pathway in osteoblastic cells. Ubiquitin/proteasome-dependent regulation," Journal of Biological Chemistry, vol. 274, no. 41, pp. 28875-28879, 1999.

[89] A. Rajgopal, D. W. Young, K. A. Mujeeb et al., "Mitotic control of RUNX2 phosphorylation by both CDK1/cyclin B kinase and PP1/PP2A phosphatase in osteoblastic cells," Journal of Cellular Biochemistry, vol. 100, no. 6, pp. 15091517, 2007.

[90] X. Li, L. H. Hoeppner, E. D. Jensen, R. Gopalakrishnan, and J. J. Westendorf, "Co-activator activator (CoAA) prevents the transcriptional activity of runt domain transcription factors," Journal of Cellular Biochemistry, vol. 108, no. 2, pp. 378-387, 2009.

[91] E.-J. Jeon, K.-Y. Lee, N.-S. Choi et al., "Bone morphogenetic protein-2 stimulates Runx2 acetylation," Journal of Biological Chemistry, vol. 281, no. 24, pp. 16502-16511, 2006.

[92] R. Jemtland, P. Divieti, K. Lee, and G. V. Segre, "Hedgehog promotes primary osteoblast differentiation and increases PTHrP mRNA expression and iPTHrP secretion," Bone, vol. 32, no. 6, pp. 611-620, 2003.

[93] S. Spinella-Jaegle, G. Rawadi, S. Kawai et al., "Sonic hedgehog increases the commitment of pluripotent mesenchymal cells into the osteoblastic lineage and abolishes adipocytic differentiation," Journal of Cell Science, vol. 114, no. 11, pp. 2085-2094, 2001.

[94] H. Zhou, W. Mak, Y. Zheng, C. R. Dunstan, and M. J. Seibel, "Osteoblasts directly control lineage commitment of mesenchymal progenitor cells through Wnt signaling," Journal of Biological Chemistry, vol. 283, no. 4, pp. 19361945, 2008.

[95] M. I. Reinhold and M. C. Naski, "Direct interactions of Runx2 and canonical Wnt signaling induce FGF18," Journal of Biological Chemistry, vol. 282, no. 6, pp. 3653-3663, 2007.

[96] N. Ohbayashi, M. Shibayama, Y. Kurotaki et al., "FGF18 is required for normal cell proliferation and differentiation during osteogenesis and chondrogenesis," Genes and Development, vol. 16, no. 7, pp. 870-879, 2002.

[97] Y. Nishio, Y. Dong, M. Paris, R. J. O’Keefe, E. M. Schwarz, and H. Drissi, "Runx2-mediated regulation of the zinc finger Osterix/Sp7 gene," Gene, vol. 372, no. 1-2, pp. 62-70, 2006.

[98] M. V. Bais, N. Wigner, M. Young et al., "BMP2 is essential for post natal osteogenesis but not for recruitment of osteogenic stem cells," Bone, vol. 45, no. 2, pp. 254-266, 2009.

[99] T. Matsubara, K. Kida, A. Yamaguchi et al., "BMP2 regulates osterix through Msx2 and Runx2 during osteoblast differentiation," Journal of Biological Chemistry, vol. 283, no. 43, pp. 29119-29125, 2008.

[100] A. Javed, J.-S. Bae, F. Afza et al., "Structural coupling of Smad and Runx2 for execution of the BMP2 osteogenic signal," Journal of Biological Chemistry, vol. 283, no. 13, pp. 84128422, 2008.

[101] M. Kato, M. S. Patel, R. Levasseur et al., "Cbfa1-independent decrease in osteoblast proliferation, osteopenia, and persistent embryonic eye vascularization in mice deficient in Lrp5, a Wnt coreceptor," Journal of Cell Biology, vol. 157, no. 2, pp. 303-314, 2002.

[102] G. Rawadi, B. Vayssière, F. Dunn, R. Baron, and S. RomanRoman, "BMP-2 controls alkaline phosphatase expression and osteoblast mineralization by a Wnt autocrine loop," Journal of Bone and Mineral Research, vol. 18, no. 10, pp. 1842-1853, 2003.
[103] M. Almeida, L. Han, T. Bellido, S. C. Manolagas, and S. Kousteni, "Wnt proteins prevent apoptosis of both uncommitted osteoblast progenitors and differentiated osteoblast by $\beta$-catenin-dependent and -independent signaling cascades involving Src/ERK and phosphatidylinositol 3-kinase/AKT," Journal of Biological Chemistry, vol. 280, no. 50, pp. 4134241351, 2005.

[104] J. Pratap, M. Galindo, S. K. Zaidi et al., "Cell growth regulatory role of Runx2 during proliferative expansion of preosteoblasts," Cancer Research, vol. 63, no. 17, pp. 53575362, 2003.

[105] D. W. Young, M. Q. Hassan, J. Pratap et al., "Mitotic occupancy and lineage-specific transcriptional control of rRNA genes by Runx2," Nature, vol. 445, no. 7126, pp. 442446, 2007.

[106] D. W. Young, M. Q. Hassan, X.-Q. Yang et al., "Mitotic retention of gene expression patterns by the cell fatedetermining transcription factor Runx2," Proceedings of the National Academy of Sciences of the United States of America, vol. 104, no. 9, pp. 3189-3194, 2007.

[107] S. K. Zaidi, D. W. Young, M. A. Montecino et al., "Mitotic bookmarking of genes: a novel dimension to epigenetic control," Nature Reviews Genetics, vol. 11, no. 8, pp. 583-589, 2010.

[108] R. A. Eliseev, Y.-F. Dong, E. Sampson et al., "Runx2mediated activation of the Bax gene increases osteosarcoma cell sensitivity to apoptosis," Oncogene, vol. 27, no. 25, pp. 3605-3614, 2008.

[109] N. M. Teplyuk, M. Galindo, V. I. Teplyuk et al., "Runx2 regulates $G$ protein-coupled signaling pathways to control growth of osteoblast progenitors," Journal of Biological Chemistry, vol. 283, no. 41, pp. 27585-27597, 2008.

[110] J. J. Westendorf, S. K. Zaidi, J. E. Cascino et al., "Runx2 (Cbfa1, AML-3) interacts with histone deacetylase 6 and represses the p21CIP1/WAF1 promoter," Molecular and Cellular Biology, vol. 22, no. 22, pp. 7982-7992, 2002.

[111] W.-P. Ho, W.-P. Chan, M.-S. Hsieh, and R.-M. Chen, "Runx2-mediated bcl-2 gene expression contributes to nitric oxide protection against hydrogen peroxide-induced osteoblast apoptosis," Journal of Cellular Biochemistry, vol. 108, no. 5, pp. 1084-1093, 2009.

[112] C. Zaragoza, E. López-Rivera, C. García-Rama et al., "Cbfa-1 mediates nitric oxide regulation of MMP-13 in osteoblasts," Journal of Cell Science, vol. 119, no. 9, pp. 1896-1902, 2006.

[113] N. Ortega, D. J. Behonick, and Z. Werb, "Matrix remodeling during endochondral ossification," Trends in Cell Biology, vol. 14, no. 2, pp. 86-93, 2004.

[114] T. Fujita, Y. Azuma, R. Fukuyama et al., "Runx2 induces osteoblast and chondrocyte differentiation and enhances their migration by coupling with PI3K-Akt signaling," Journal of Cell Biology, vol. 166, no. 1, pp. 85-95, 2004.

[115] R. Fukuyama, T. Fujita, Y. Azuma et al., "Statins inhibit osteoblast migration by inhibiting Rac-Akt signaling," Biochemical and Biophysical Research Communications, vol. 315, no. 3, pp. 636-642, 2004.

[116] F. J. Hughes, J. E. Aubin, and J. N. M. Heersche, "Differential chemotactic responses of different populations of fetal rat calvaria cells to platelet-derived growth factor and transforming growth factor $\beta$," Bone and Mineral, vol. 19, no. 1, pp. 6374, 1992.

[117] F. S. Panagakos, "Insulin-like growth factors-I and -II stimulate chemotaxis of osteoblasts isolated from fetal rat calvaria," Biochimie, vol. 75, no. 11, pp. 991-994, 1993. 
[118] D. M. Thomas, S. A. Johnson, N. A. Sims et al., "Terminal osteoblast differentiation, mediated by runx2 and p27 KIP1, is disrupted in osteosarcoma," Journal of Cell Biology, vol. 167, no. 5, pp. 925-934, 2004.

[119] S. D. Berman, E. Calo, A. S. Landman et al., "Metastatic osteosarcoma induced by inactivation of $\mathrm{Rb}$ and $\mathrm{p} 53$ in the osteoblast lineage," Proceedings of the National Academy of Sciences of the United States of America, vol. 105, no. 33, pp. 11851-11856, 2008.

[120] J.-S. Lee, D. M. Thomas, G. Gutierrez, S. A. Carty, S.-I. Yanagawa, and P. W. Hinds, "HES1 cooperates with $\mathrm{pRb}$ to activate RUNX2-dependent transcription," Journal of Bone and Mineral Research, vol. 21, no. 6, pp. 921-933, 2006.

[121] D. M. Thomas, S. A. Carty, D. M. Piscopo et al., "The retinoblastoma protein acts as a transcriptional coactivator required for osteogenic differentiation," Molecular Cell, vol. 8, no. 2, pp. 303-316, 2001.

[122] J. Sierra, A. Villagra, R. Paredes et al., "Regulation of the bone-specific osteocalcin gene by p 300 requires Runx $2 / \mathrm{Cbfa} 1$ and the vitamin $\mathrm{D}_{3}$ receptor but not $\mathrm{p} 300$ intrinsic histone acetyltransferase activity," Molecular and Cellular Biology, vol. 23, no. 9, pp. 3339-3351, 2003.

[123] N. Pelletier, N. Champagne, S. Stifani, and X.-J. Yang, "MOZ and MORF histone acetyltransferases interact with the Runtdomain transcription factor Runx2," Oncogene, vol. 21, no. 17, pp. 2729-2740, 2002.

[124] T. M. Schroeder, R. A. Kahler, X. Li, and J. J. Westendorf, "Histone deacetylase 3 interacts with Runx2 to repress the osteocalcin promoter and regulate osteoblast differentiation," Journal of Biological Chemistry, vol. 279, no. 40, pp. 4199842007, 2004.

[125] J. J. Westendorf, “Transcriptional co-repressors of Runx2," Journal of Cellular Biochemistry, vol. 98, no. 1, pp. 54-64, 2006.

[126] S. K. Zaidi, A. J. Sullivan, R. Medina et al., "Tyrosine phosphorylation controls Runx2-mediated subnuclear targeting of YAP to repress transcription," The EMBO Journal, vol. 23, no. 4, pp. 790-799, 2004.

[127] R. B. Vega, K. Matsuda, J. Oh et al., "Histone deacetylase 4 controls chondrocyte hypertrophy during skeletogenesis," Cell, vol. 119, no. 4, pp. 555-566, 2004.

[128] V. B. Andela, F. Siddiqui, A. Groman, and R. N. Rosier, "An immunohistochemical analysis to evaluate an inverse correlation between Runx2/Cbfa1 and $\mathrm{NF} \kappa \mathrm{B}$ in human osteosarcoma," Journal of Clinical Pathology, vol. 58, no. 3, pp. 328-330, 2005.

[129] Z. Maruyama, C. A. Yoshida, T. Furuichi et al., "Runx2 determines bone maturity and turnover rate in postnatal bone development and is involved in bone loss in estrogen deficiency," Developmental Dynamics, vol. 236, no. 7, pp. 1876-1890, 2007.

[130] N. Tang, W.-X. Song, J. Luo, R. C. Haydon, and T.-C. He, "Osteosarcoma development and stem cell differentiation," Clinical Orthopaedics and Related Research, vol. 466, no. 9, pp. 2114-2130, 2008.

[131] K. Y. Won, H.-R. Park, and Y.-K. Park, "Prognostic implication of immunohistochemical Runx2 expression in osteosarcoma," Tumori, vol. 95, no. 3, pp. 311-316, 2009.

[132] K. C. Kurek, S. Del Mare, Z. Salah et al., "Frequent attenuation of the WWOX tumor suppressor in osteosarcoma is associated with increased tumorigenicity and aberrant RUNX2 expression," Cancer Research, vol. 70, no. 13, pp. 5577-5586, 2010.
[133] S. D. Berman, T. L. Yuan, E. S. Miller, E. Y. Lee, A. Caron, and J. A. Lees, "The retinoblastoma protein tumor suppressor is important for appropriate osteoblast differentiation and bone development," Molecular Cancer Research, vol. 6, no. 9, pp. 1440-1451, 2008.

[134] D. W. Goodrich, "The retinoblastoma tumor-suppressor gene, the exception that proves the rule," Oncogene, vol. 25, no. 38, pp. 5233-5243, 2006.

[135] T. van Harn, F. Foijer, M. van Vugt et al., "Loss of Rb proteins causes genomic instability in the absence of mitogenic signaling," Genes and Development, vol. 24, no. 13, pp. 13771388, 2010.

[136] G. P. Zambetti, E. M. Horwitz, and E. Schipani, "Skeletons in the p53 tumor suppressor closet: genetic evidence that p53 blocks bone differentiation and development," Journal of Cell Biology, vol. 172, no. 6, pp. 795-797, 2006.

[137] C. R. Walkley, R. Qudsi, V. G. Sankaran et al., "Conditional mouse osteosarcoma, dependent on $\mathrm{p} 53$ loss and potentiated by loss of Rb, mimics the human disease," Genes and Development, vol. 22, no. 12, pp. 1662-1676, 2008.

[138] C. J. Lengner, H. A. Steinman, J. Gagnon et al., "Osteoblast differentiation and skeletal development are regulated by Mdm2-p53 signaling," Journal of Cell Biology, vol. 172, no. 6, pp. 909-921, 2006.

[139] A. Vidal and A. Koff, "Cell-cycle inhibitors: three families united by a common cause," Gene, vol. 247 , no. 1-2, pp. 1$15,2000$.

[140] F. Engin, Z. Yao, T. Yang et al., "Dimorphic effects of Notch signaling in bone homeostasis," Nature Medicine, vol. 14, no. 3, pp. 299-305, 2008.

[141] R. Shen, X. Wang, H. Drissi, F. Liu, R. J. O’Keefe, and D. Chen, "Cyclin D1-Cdk4 induce Runx2 ubiquitination and degradation," Journal of Biological Chemistry, vol. 281, no. 24, pp. 16347-16353, 2006.

[142] P. Zhang, Y. Yang, P. A. Zweidler-McKay, and D. P. M. Hughes, "Critical role of notch signaling in osteosarcoma invasion and metastasis," Clinical Cancer Research, vol. 14, no. 10, pp. 2962-2969, 2008.

[143] S. K. Zaidi, S. Pande, J. Pratap et al., "Runx2 deficiency and defective subnuclear targeting bypass senescence to promote immortalization and tumorigenic potential," Proceedings of the National Academy of Sciences of the United States of America, vol. 104, no. 50, pp. 19861-19866, 2007.

[144] J. M. Bailey, P. K. Singh, and M. A. Hollingsworth, "Cancer metastasis facilitated by developmental pathways: sonic hedgehog, notch, and bone morphogenic proteins," Journal of Cellular Biochemistry, vol. 102, no. 4, pp. 829-839, 2007.

[145] A. S. Dhillon, S. Hagan, O. Rath, and W. Kolch, "MAP kinase signalling pathways in cancer," Oncogene, vol. 26, no. 22, pp. 3279-3290, 2007.

[146] F. Engin, T. Bertin, O. Ma et al., "Notch signaling contributes to the pathogenesis of human osteosarcomas," Human Molecular Genetics, vol. 18, no. 8, pp. 1464-1470, 2009.

[147] E. M. Rubin, Y. Guo, K. Tu, J. Xie, X. Zi, and B. H. Hoang, "Wnt inhibitory factor 1 decreases tumorigenesis and metastasis in osteosarcoma," Molecular Cancer Therapeutics, vol. 9, no. 3, pp. 731-741, 2010.

[148] J. Akech, J. J. Wixted, K. Bedard et al., "Runx2 association with progression of prostate cancer in patients: mechanisms mediating bone osteolysis and osteoblastic metastatic lesions," Oncogene, vol. 29, no. 6, pp. 811-821, 2010.

[149] R. Kitazawa, K. Mori, A. Yamaguchi, T. Kondo, and S. Kitazawa, "Modulation of mouse RANKL gene expression 
by runx2 and vitamin D 3," Journal of Cellular Biochemistry, vol. 105, no. 5, pp. 1289-1297, 2008.

[150] K. K. Mak, Y. Bi, C. Wan et al., "Hedgehog signaling in mature osteoblasts regulates bone formation and resorption by controlling PTHrP and RANKL expression," Developmental Cell, vol. 14, no. 5, pp. 674-688, 2008.

[151] M. S. Bendre, A. G. Margulies, B. Walser et al., "Tumorderived interleukin-8 stimulates osteolysis independent of the receptor activator of nuclear factor- $\kappa \mathrm{B}$ ligand pathway," Cancer Research, vol. 65, no. 23, pp. 11001-11009, 2005.

[152] K. Mori, B. Le Goff, M. Berreur et al., "Human osteosarcoma cells express functional receptor activator of nuclear factorkappa B," Journal of Pathology, vol. 211, no. 5, pp. 555-562, 2007.

[153] M. Lim, C. Zhong, S. Yang, A. M. Bell, M. B. Cohen, and P. Roy-Burman, "Runx2 regulates survivin expression in prostate cancer cells," Laboratory Investigation, vol. 90, no. 2, pp. 222-233, 2010.

[154] J. Pratap, A. Javed, L. R. Languino et al., "The Runx2 osteogenic transcription factor regulates matrix metalloproteinase 9 in bone metastatic cancer cells and controls cell invasion," Molecular and Cellular Biology, vol. 25, no. 19, pp. 8581-8591, 2005.

[155] M. van der Deen, J. Akech, T. Wang et al., "The cancerrelated Runx2 protein enhances cell growth and responses to androgen and TGF $\beta$ in prostate cancer cells," Journal of Cellular Biochemistry, vol. 109, no. 4, pp. 828-837, 2010.

[156] K. D. Brubaker, R. L. Vessella, L. G. Brown, and E. Corey, "Prostate cancer expression of runt-domain transcription factor Runx2, a key regulator of osteoblast differentiation and function," Prostate, vol. 56, no. 1, pp. 13-22, 2003.

[157] G. L. Barnes, K. E. Hebert, M. Kamal et al., "Fidelity of Runx2 activity in breast cancer cells is required for the generation of metastases-associated osteolytic disease," Cancer Research, vol. 64, no. 13, pp. 4506-4513, 2004.

[158] J. Pratap, J. J. Wixted, T. Gaur et al., "Runx2 transcriptional activation of Indian Hedgehog and a downstream bone metastatic pathway in breast cancer cells," Cancer Research, vol. 68, no. 19, pp. 7795-7802, 2008.

[159] K. Blyth, F. Vaillant, L. Hanlon et al., "Runx2 and MYC collaborate in lymphoma development by suppressing apoptotic and growth arrest pathways in vivo," Cancer Research, vol. 66, no. 4, pp. 2195-2201, 2006.

[160] H.-Y. Zhang, L. Jin, G. A. Stilling et al., "RUNX1 and RUNX2 upregulate Galectin-3 expression in human pituitary tumors," Endocrine, vol. 35, no. 1, pp. 101-111, 2009.

[161] C. Khanna, J. Khan, P. Nguyen et al., "Metastasis-associated differences in gene expression in a murine model of osteosarcoma," Cancer Research, vol. 61, no. 9, pp. 3750-3759, 2001.

[162] T. Bellido, A. A. Ali, L. I. Plotkin et al., "Proteasomal degradation of Runx2 shortens parathyroid hormone-induced antiapoptotic signaling in osteoblasts: a putative explanation for why intermittent administration is needed for bone anabolism," Journal of Biological Chemistry, vol. 278, no. 50, pp. 50259-50272, 2003.

[163] U. Ruther, D. Komitowski, F. R. Schubert, and E. F. Wagner, "c-fos expression induces bone tumors in transgenic mice," Oncogene, vol. 4, no. 7, pp. 861-865, 1989.

[164] R. C. D’Alonzo, N. Selvamurugan, G. Karsenty, and N. C. Partridge, "Physical interaction of the activator protein-1 factors c-Fos and c-Jun with Cbfal for collagenase-3 promoter activation," Journal of Biological Chemistry, vol. 277, no. 1, pp. 816-822, 2002.
[165] D. J. Papachristou, G. J. Papachristou, O. A. Papaefthimiou, N. J. Agnantis, E. K. Basdra, and A. G. Papavassiliou, "The MAPK-AP-1/-Runx2 signalling axes are implicated in chondrosarcoma pathobiology either independently or via up-regulation of VEGF," Histopathology, vol. 47, no. 6, pp. 565-574, 2005.

[166] A.-M. Cleton-Jansen, J. K. Anninga, I. H. Briaire-de Bruijn et al., "Profiling of high-grade central osteosarcoma and its putative progenitor cells identifies tumourigenic pathways," British Journal of Cancer, vol. 101, no. 11, pp. 1909-1918, 2009.

[167] R. C. Haydon, H. H. Luu, and T.-C. He, "Osteosarcoma and osteoblastic differentiation: a new perspective on oncogenesis," Clinical Orthopaedics and Related Research, no. 454, pp. 237-246, 2007.

[168] A. B. Mohseny, K. Szuhai, S. Romeo et al., "Osteosarcoma originates from mesenchymal stem cells in consequence of aneuploidization and genomic loss of Cdkn2," Journal of Pathology, vol. 219, no. 3, pp. 294-305, 2009.

[169] L. Carpio, J. Gladu, D. Goltzman, and S. A. Rabbani, "Induction of osteoblast differentiation indexes by PTHrP in MG-63 cells involves multiple signaling pathways," American Journal of Physiology, vol. 281, no. 3, pp. E489-E499, 2001.

[170] G. Olfa, C. Christophe, L. Philippe et al., "RUNX2 regulates the effects of TNF $\alpha$ on proliferation and apoptosis in SaOs-2 cells," Bone, vol. 46, no. 4, pp. 901-910, 2010.

[171] L. Postiglione, G. Di Domenico, S. Montagnani et al., "Granulocyte-macrophage colony-stimulating factor (GMCSF) induces the osteoblastic differentiation of the human osteosarcoma cell line SaOS-2," Calcified Tissue International, vol. 72, no. 1, pp. 85-97, 2003.

[172] H. Siggelkow, M. Schenck, M. Rohde et al., "Prolonged culture of HOS 58 human osteosarcoma cells with 1,25- $(\mathrm{OH})_{2}$ $\mathrm{D}_{3}$, TGF-beta, and dexamethasone reveals physiological regulation of alkaline phosphatase, dissociated osteocalcin gene expression, and protein synthesis and lack of mineralization," Journal of Cellular Biochemistry, vol. 85, no. 2, pp. 279-294, 2002.

[173] J. Yang, X. Zhang, W. Wang, and J. Liu, "Insulin stimulates osteoblast proliferation and differentiation through ERK and PI3K in MG-63 cells," Cell Biochemistry and Function, vol. 28, no. 4, pp. 334-341, 2010.

[174] B. Sadikovic, M. Yoshimoto, S. Chilton-MacNeill, P. Thorner, J. A. Squire, and M. Zielenska, "Identification of interactive networks of gene expression associated with osteosarcoma oncogenesis by integrated molecular profiling," Human Molecular Genetics, vol. 18, no. 11, pp. 1962-1975, 2009. 


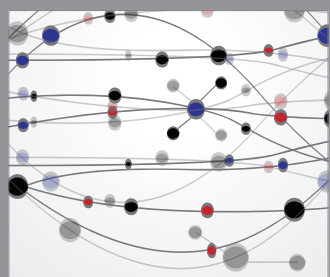

The Scientific World Journal
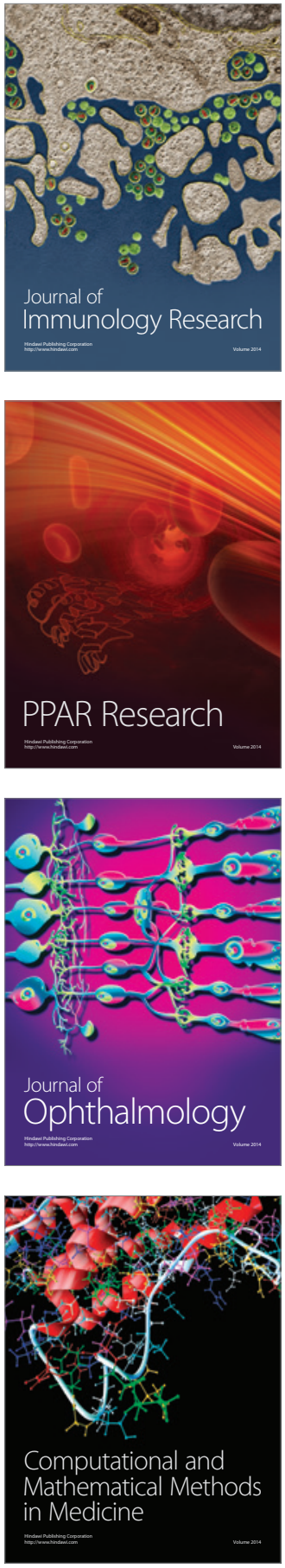

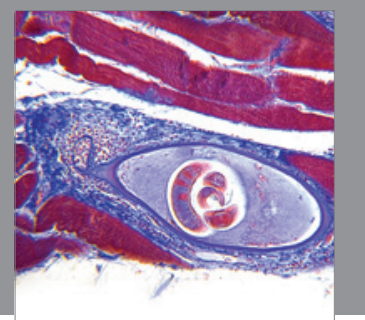

Gastroenterology

Research and Practice
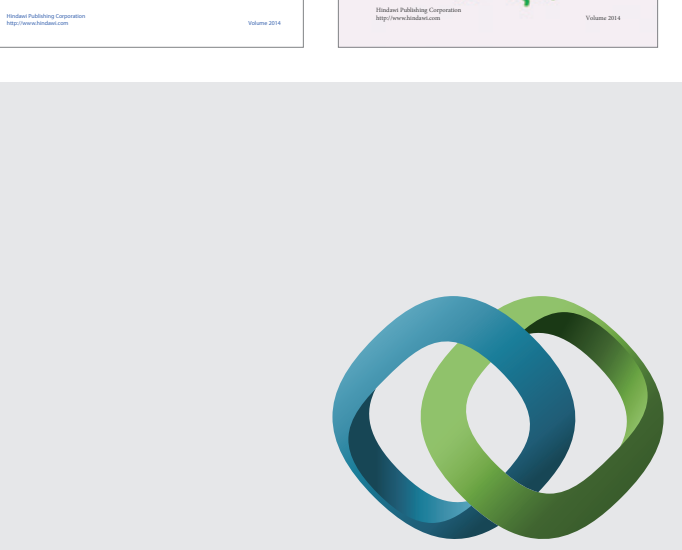

\section{Hindawi}

Submit your manuscripts at

http://www.hindawi.com
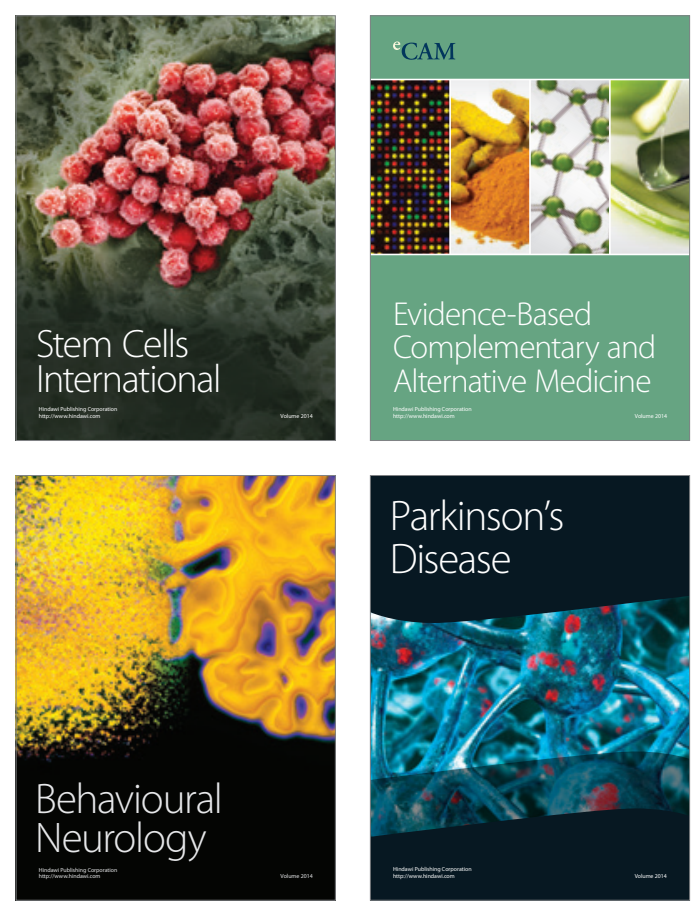

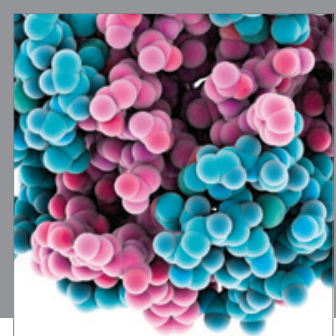

Journal of
Diabetes Research

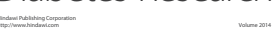

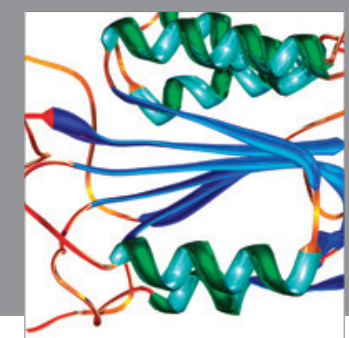

Disease Markers
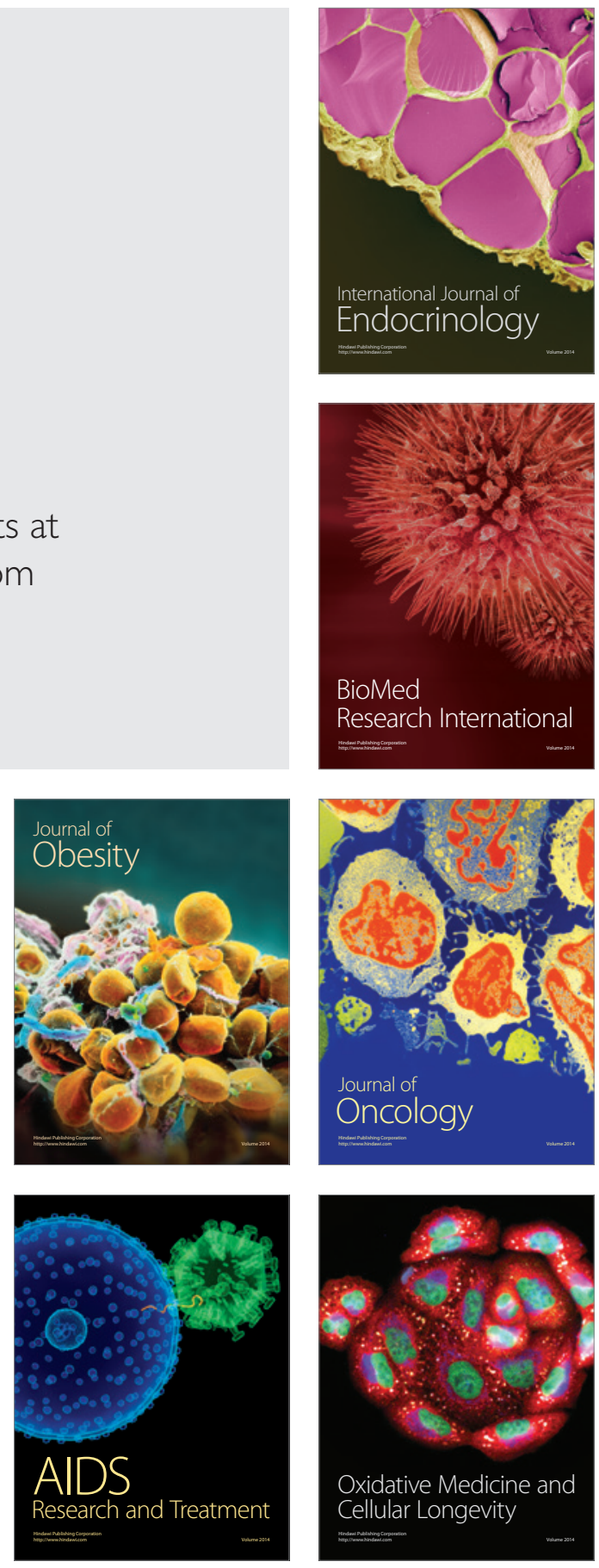